(C) 2021, The Authors. Published by Elsevier Inc. and Fass Inc. on behalf of the American Dairy Science Association ${ }^{\circledR}$. This is an open access article under the CC BY-NC-ND license (http://creativecommons.org/licenses/by-nc-nd/4.0/).

\title{
Short communication: The lag response of daily milk yield to heat stress in dairy cows
}

Gan Li, (1) Jian Chen, (1) Dandan Peng, (1) and Xianhong Gu* (1)

State Key Laboratory of Animal Nutrition, Institute of Animal Science, Chinese Academy of Agricultural Sciences, Beijing 100193, P. R. China

\begin{abstract}
Previous studies suggest that there exists a lag relationship between daily milk yield and heat stress. The values of heat stress indicators (e.g., temperaturehumidity index and ambient temperature) before test day have a simple correlation with daily milk yield on test day. However, the simple correlation might not be the best description because daily milk yield and heat stress indicators have a nature of time series in common, and their correlations are cross correlations that could be affected by autocorrelations. We hope to give a more reliable estimation on the lag relationship of daily milk yield via excluding autocorrelations with transfer function modeling. In this study, we found a lag relationship between daily milk yield and heat stress indicators based on transfer function modeling. Heat stress indicators included ambient temperature and temperature-humidity index. The daily milk yield data from 123 cows were obtained during a consecutive 63-d period (July 10-September 10, 2016). The mean daily milk yield (MY) and the maximum daily ambient temperature (TA_max) satisfied the stationary hypothesis, and the cross correlation between them was calculated. Before excluding autocorrelation, MY at 0 to $4 \mathrm{~d}$ after test day had significant cross correlations with TA_max on test day. After excluding the influence of autocorrelations, MY at 1 to $3 \mathrm{~d}$ after the test day had significant cross correlations with TA_max on test day. This result suggested that MY would respond to TA_max $1 \mathrm{~d}$ after the test day. In addition, the strength of cross correlations between MY and TA_max decreased from 1 to $3 \mathrm{~d}$ in sequence, implying a declining lag response of MY that would last for $3 \mathrm{~d}$. The transfer function model for MY and TA_max is written as: $M Y_{t}$ $=16.90+0.74 M Y_{t-1}-0.25 T_{A} \_$max $_{t-1}+N_{t}$, where $N_{t}$ is white noise. This model can be used to track and predict the dynamic response of MY to TA_max.
\end{abstract}

Received January 9, 2020.

Accepted August 7, 2020.

*Corresponding author: guxianhong@vip.sina.com
Key words: dairy cow, heat stress, milk yield, dynamic system, transfer function model

\section{Short Communication}

The negative effect of heat stress on milk production is one of the central problems in milk production (West, 2003; Smith et al., 2013; Collier et al., 2017). The output of milk yield can change with the variation of heat stress (Bouraoui et al., 2002; Collier et al., 2006; Bohlouli et al., 2013). Many previous studies indicate that the response of daily milk yield to heat stress indicators [e.g., temperature-humidity index (THI) and ambient temperature $\left.\left(\mathbf{T A},{ }^{\circ} \mathrm{C}\right)\right]$ is not instantaneous, but has a lag of a few days according to the simple correlations between daily milk yield on test day and the values of heat stress indicators before test day (Collier et al., 1981; Wildridge et al., 2018). Collier et al. (1981) reported that the decline of daily milk yield had a simple correlation with black globe temperature of 1 or $2 \mathrm{~d}$ before test day. Wildridge et al. (2018) indicated that the THI values 0 to $3 \mathrm{~d}$ before test day were associated with daily milk yield. West (2003) reported daily milk yield has the strongest correlation with the THI of $2 \mathrm{~d}$ before test day. However, the simple correlation might not be the best description for the relationship between daily milk yield and heat stress indicators because the simple correlation implies a data structure without autocorrelations between consecutive observations, which is not in line with the nature of time series for both daily milk yield and heat stress indicators (Deluyker et al., 1990; Jensen et al., 2018). That is, the observations for daily temperature and heat stress indicators are generated over time, and thus the autocorrelations between consecutive observations should be considered. In recent studies, the issue of autocorrelations was considered (Zeng et al., 2009; Ammer et al., 2016; Heinicke et al., 2019). Under the framework of time series analysis, daily milk yield and heat stress indicators can be viewed as the output and input series of a dynamic system, respectively. In this dynamic system, the lag response of output series can be interpreted with the "inertia" of system. That is, 
a change in input series might have no immediate effect on output series, but produce a lag response with output eventually coming to equilibrium (Bisgaard and Kulahci, 2011). The correlation relationship between input and output series is called cross correlation, and the cross correlations at different orders of lag constitute a cross-correlation function $(\mathbf{C C F})$. A model that describes the abovementioned dynamic system is called a transfer function model, with transfer function connecting input and output series. The CCF and transfer function are the basis for recognizing the pattern of the lag response of output series. In this study, we hypothesize that daily milk yield and heat stress indicators constitute a dynamic system. We input TA or THI as input series and mean daily milk yield (MY) as output series. The CCF and transfer function model were developed to identify the pattern of the lag response of output series.

The CCF between 2 series, $x_{t}$ and $y_{t}$, is the function for cross-correlation coefficients $\left(\rho_{x y}\right)$ as follows:

$$
\mathrm{CCF}=\rho_{x y}(k)=c_{x y} \times\left(s_{x} \times s_{y}\right)^{-1},
$$

where $k$ is the order of lag, and $s_{x}$ and $s_{y}$ are the sample standard deviations of $x_{t}$ and $y_{t}$, respectively. Additionally, $c_{x y}$ is the cross covariance between $x_{t}$ and $y_{t}$, as follows:

$$
\begin{gathered}
c_{x y}=\frac{1}{n} \sum_{t=1}^{n-k}\left(x_{t}-\bar{x}\right)\left(y_{t+k}-\bar{y}\right), k=0,1,2, \ldots, \text { or } \\
c_{x y}=\frac{1}{n} \sum_{t=1}^{n-k}\left(y_{t}-\bar{y}\right)\left(x_{t-k}-\bar{x}\right), k=0,-1,-2, \ldots,
\end{gathered}
$$

where $\bar{x}$ and $\bar{y}$ denote the sample means of $x_{t}$ and $y_{t}$, respectively. The function relationship between input and output series, $x_{t}$ and $y_{t}$, is $y_{t}=f\left(x_{t}\right)$, with $f$ denoting transfer function. Note that the CCF is not symmetric for positive and negative time lags. If $x_{t}$ and $y_{t}$ are assumed to be input and output respectively, the positive part of time lags denotes the lag response of $y_{t}$ to $x_{t}$ [i.e., the cross correlations between the $y_{t+k}$ and $x_{t}(k=0,1$, $2, \ldots)]$.

Furthermore, the transfer function model can be written as follows:

$$
\begin{gathered}
y_{t}=\omega(B)^{-1} \delta(B) B^{b} x_{t}+N_{t}, \\
\omega(B)=1-\lambda_{1} B-\ldots-\lambda_{s} B^{r}, \\
\delta(B)=\zeta_{0}-\zeta_{1} B-\ldots-\zeta_{r} B^{s},
\end{gathered}
$$

where $y_{t}$ and $x_{t}$ represent the output and input series, respectively; $B$ denotes backshift operator $\left(B^{k} x_{t}=x_{t-k}\right.$; $k=0,1,2, \ldots) ; \omega(B)$ and $\delta(B)$ are polynomials of $B ; r$ and $s$ are the orders of $B$ in $\omega(B)$ and $\delta(B)$, respectively; $\omega(B)^{-1} \delta(B) B^{b}$ is the transfer function; $b$ is the order of time delay $\left(B^{b} x_{t}=x_{t-b}\right) ; \lambda$ and $\zeta$ are the coefficients of $B$ in $\omega(B)$ and $\delta(B)$, respectively; and $N_{t}$ is noise (residual). If $N_{t}$ does not satisfy the white noise assumption, $N_{t}$ should be converted into white noise process via an autoregressive moving average modeling. White noise process (i.e., purely random process) has zero mean, constant variance, and no autocorrelations. The autoregressive moving average model is as follows:

$$
\begin{gathered}
z_{t}=\Phi(B)^{-1} \Theta(B) \varepsilon_{t} \\
\Phi(B)=1-\phi_{1} B-\phi_{2} B^{2}-\ldots-\phi_{p} B^{p}, \\
\Theta(B)=1-\theta_{1} B-\theta_{2} B^{2}-\ldots-\theta_{q} B^{q},
\end{gathered}
$$

where $\Phi(B)$ and $\Theta(B)$ represent autoregressive (AR) and moving average processes, respectively; $z_{t}$ and $\varepsilon_{t}$ represent time series and residual, respectively; $\phi$ and $\theta$ are coefficients of $B$ in $\Phi(B)$ and $\Theta(B)$, respectively; and $p$ and $q$ are the orders of $B$ in $\Phi(B)$ and $\Theta(B)$, respectively.

The CCF is the foundation of recognizing the orders $(r, s, b)$ in transfer function modeling. There is a risk of spurious cross correlations for CCF because the autocorrelations for input and output series could interfere the estimation of cross-correlation coefficients. To avoid spurious cross correlations, the input and output series were prewhitened to exclude the effects of autocorrelations. The input series $\left(x_{t}\right)$ are prewhitened with a linear filter as follows:

$$
\alpha_{t}=\varphi^{-1}(B) \psi(B) x_{t}
$$

where $\alpha_{t}$ is the prewhitened input series and $\varphi^{-1}(B)$ $\psi(B)$ is the linear filter $[\varphi(B)$ and $\psi(B)$ denote AR and moving average processes, respectively]. In addition, the linear filter is used for filtering the output series $\left(y_{t}\right)$ as follows:

$$
\beta_{t}=\varphi^{-1}(B) \psi(B) y_{t},
$$

where $\beta_{t}$ is the prewhitened output series. The CCF for $\alpha_{t}$ and $\beta_{t}$ can be used to recognize the orders $(r, s, b)$ of the transfer function model.

All procedures were approved by the Chinese Academy of Agricultural Sciences Animal Care and Use Committee. Animal welfare concern is not required because the study has no operation involving animals. 
The data set of cows' information was provided by a Holstein dairy farm located in Shunyi, Beijing, China. The cows with milk yield lower than $15 \mathrm{~kg} / \mathrm{d}$ and DIM higher than 300 (DIM of the first test day) were excluded. The data set includes daily milk yield $(\mathrm{kg} / \mathrm{d})$, parity, and DIM from 123 cows for 63 consecutive test days (July 10-September 10 in 2016; 7749 records). The milk yield, parity, and DIM of cows on the first test day (July 10) averaged $36.7 \mathrm{~kg} / \mathrm{d}$ (ranging from $15.2-50.5 \mathrm{~kg} / \mathrm{d}$ with a SD of 7.6), 2.7 (ranging from 1-5 with a SD of 1.1), and 91 (ranging from 17-235 with a SD of 58), respectively. The cows were milked 3 times a day at 0800 to 0930,1200 to 1330 , and 1800 to $1930 \mathrm{~h}$, respectively. During the test days, cows were cooled with sprayed water 3 times per day when cows were milked. The cowsheds were equipped with fans and shade structures, and without sprayed water equipment. The dairy farm moved the cows with health problems to a special shelter for clinical care, and the 123 cows in this study did not include the cases with health problems. The weather data including $\mathrm{TA}\left({ }^{\circ} \mathrm{C}\right)$ and relative humidity (\%) were recorded at 5-min intervals using Kestrel 5,000 environment meters (NielsenKellerman Co., Boothwyn, PA) that were mounted on the center pillars of cowsheds at $2 \mathrm{~m}$ above the ground. The THI was calculated based on $[\mathrm{THI}=(1.8 \times \mathrm{TA}$ $+32)-(0.55-0.0055 \times$ relative humidity $) \times(1.8 \times$ TA - 26); NRC, 1971].

The statistical procedures were performed using $\mathrm{R}$ software (version 3.6.3; https://www.r-project.org/). The mean daily milk yield (MY, kg/d; output series) was the average daily milk yield in each day. Three of the input series for TA were average TA (TA_avg, ${ }^{\circ} \mathrm{C}$ ), maximum TA (TA_max, ${ }^{\circ} \mathrm{C}$ ) and minimum TA (TA_min, ${ }^{\circ} \mathrm{C}$ ) on a daily basis. Another 3 input series for THI included average THI (THI_avg), maximum THI (THI_max), and minimum THI (THI_min) on a daily basis. The stationary assumption was the precondition of analysis that can avoid spurious regression problem. Before building transfer function models, the stationary of input and output series were examined with the ur.df function (augmented Dicky-Fuller test; ADF) and ur.kpss function (Kwiatkowski-PhillipsSchmidt-Shin test; KPSS) of the urca package. The nonstationary series were transformed to stationary series with differencing. After examining the stationary, the Granger causality tests were conducted to confirm the assumption of input and output series with predictive causality (Lenis et al., 2017). The Granger causality tests were performed with the grangertest function of the lmtest package. The autocorrelation function $(\mathbf{A C F})$ and partial autocorrelation function (PACF) were computed with the acf and pacf functions, respectively. The white noise tests were carried out with the box.test function. The CCF were calculated using the ccf function. The prewhitening was conducted using the filter function. The transfer function models were fitted with the sarima function in the astsa package. The identification of orders $(r, s, b)$ of the transfer function model was based on the method provided by Box et al. (2015) and Shumway and Stoffer (2017).

During the whole test period, MY varied between 33.2 and $40.5 \mathrm{~kg} / \mathrm{d}$ (Figure 1a); TA_avg, TA_max, and TA_min varied between 21.3 and $30.2^{\circ} \mathrm{C}, 24.4$ and $33.6^{\circ} \mathrm{C}$, and 15.2 and $27.2^{\circ} \mathrm{C}$, respectively (Figure $1 \mathrm{~b}$ ); and THI_avg, THI_max, and THI_min varied between 67.7 and $82.2,70.6$ and 85.3 , and 59.2 and 78.8 , respectively (Figure 1c).

The CCF between output (MY) and input (TA_avg, TA_max, TA_min, THI_avg, THI_max, and THI_ min) series (without prewhitening) are displayed in Figure 2a-f. All 6 CCF showed the similar U-shape
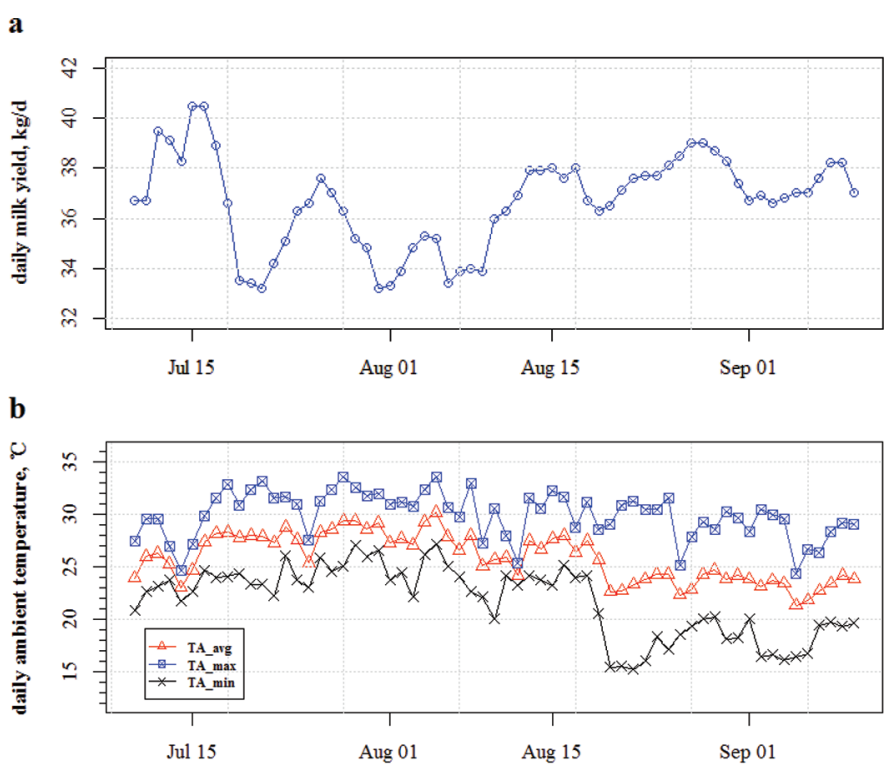

c

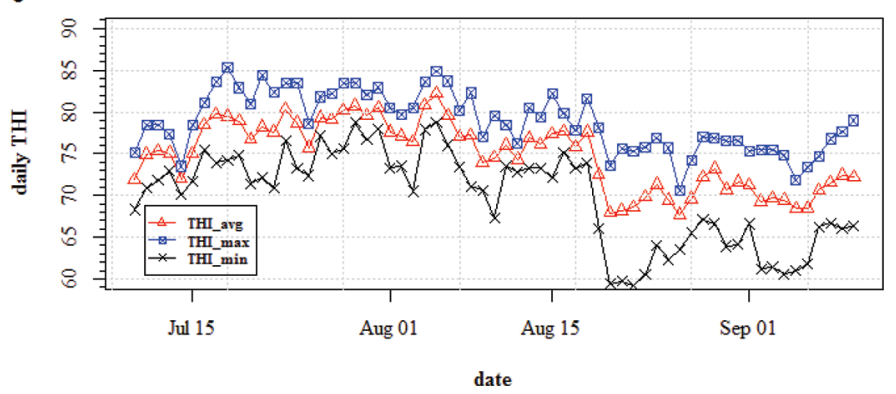

Figure 1. The time series for (a) daily milk yield (MY), (b) daily ambient temperature, and (c) daily temperature-humidity index (THI). TA_avg, TA_max, and TA_min are the average, maximum, and minimum of daily ambient temperature, respectively; THI_avg, THI_max, and THI_min are the average, maximum, and minimum for daily THI, respectively. Each point in (a) denotes the mean value of 123 cows. 
of the lag response of MY, with the highest crosscorrelation coefficient (absolute value) at the second or third order of lag (see the positive part of time lags in Figure 2a-f). The U-shape suggested that the strength of lag response of MY (according to the absolute value of cross-correlation coefficients at different lag orders) increased at first and then descended over time, and the largest lag response would appear at the second or third day after test day. West et al. (2003) reported the highest correlation between daily milk yield on test day and the THI of $2 \mathrm{~d}$ before test day, which is consistent with the results of THI in Figure 2d-f. From Figure 2a-f, all 6 inputs had significant cross correlations with TA_max on test day, suggesting that MY had response to TA_max at the same day. The lengths of lag response of MY to all 6 inputs were around 1 wk (see the numbers of significant lag in positive part). The lag response of MY to TA_avg, TA_max, and TA_min lasted $8 \mathrm{~d}$ ( 0 to seventh lag), $5 \mathrm{~d}$ (0 to fourth lag), and $10 \mathrm{~d}$ (0 to ninth lag) respectively. The lag response of MY to THI_avg, THI_max, and THI_min lasted 9 d (0 to eighth lag), $7 \mathrm{~d}$ (0 to sixth lag), and $10 \mathrm{~d}$ (0 to ninth lag), respectively.

Before prewhitening input and output series, the stationary tests were conducted, and the results are shown in Table 1. The series of MY and TA_max satisfied the stationary assumption at a significance level of $5 \%$ of ADF and KPSS. The Granger causality test supported the assumption of inputting TA_max and outputting MY, and that TA_max contained the useful information for predicting MY $(P<0.05)$. The series of TA_avg, TA_min, THI_avg, THI_max, and THI_min were not stationary at a significant level of $5 \%$ of ADF and KPSS. Furthermore, the first order of difference was conducted to convert TA_avg, TA_min, THI_avg, THI_max, and THI_min into stationary series. However, after differencing, these 5 inputs were converted into white noise series, which contained little statistical information (the information of autocorrelations lost). Thus, the prewhitened CCF and transfer function models for these 5 inputs were not given.

To prewhiten TA_max, the process of TA_max was recognized first. The ACF and PACF for TA_max are displayed in Figure 3a and 3b, respectively. According to the tails-off characteristics for ACF and cut-off characteristics for PACF, the series of TA_max is recognized as $\mathrm{AR}(1)$ process (i.e., first order autoregressive process), and the expression of the prewhitened TA_max is written as follows:

$$
\begin{gathered}
P W\left(T A \_\max \right)_{t}=(1-0.463 B) \\
T A \_\max _{t}, \sigma_{P W\left(T A \_m a x\right)}^{2}=3.79,
\end{gathered}
$$

where $P W\left(T A \_\max \right)$ is the prewhitened TA_max series, and $\sigma_{P W\left(T A \_m a x\right)}^{2}$ represents the estimated variance
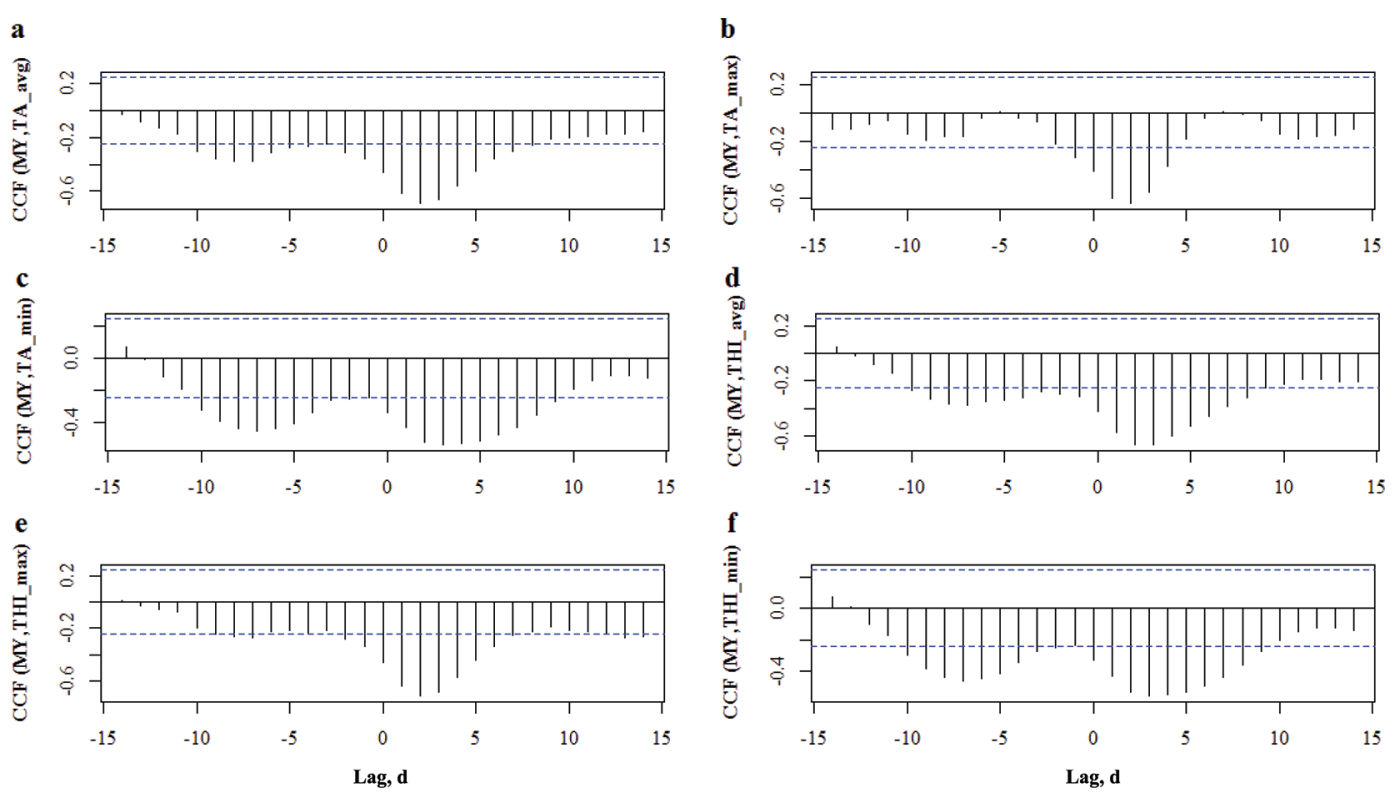

Figure 2. The cross-correlation functions (CCF) between (a) daily milk yield (MY) and TA_avg, (b) MY and TA_max, (c) MY and TA_ min, (d) MY and THI_avg, (e) MY and THI_max, and (f) MY and THI_min (without prewhitening). TA_avg, TA_max, and TA_min are the average, maximum, and minimum of daily ambient temperature, respectively; THI_avg, THI_max, and THI_min are the average, maximum, and minimum for daily THI, respectively. The spikes denote the cross-correlation coefficients. The dashed lines represent the bounds of CCF. The spikes outside the bounds will be recognized as significant cross-correlation coefficients. 


\section{a \\ b}

离
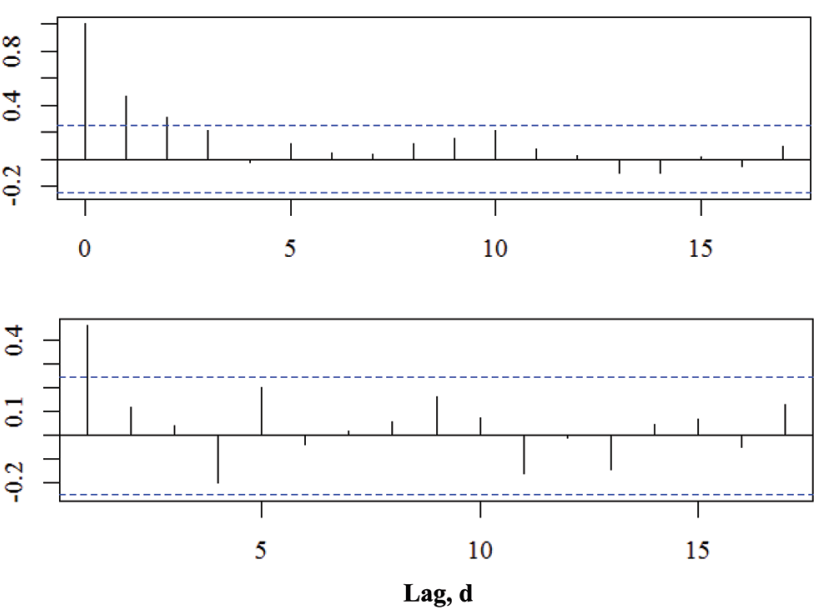

Figure 3. The (a) autocorrelation function (ACF) and (b) partial autocorrelation function (PACF) for maximum daily ambient temperature (TA_max). The dashed lines denote the bounds for ACF or PACF. The spikes outside the bounds will be recognized as significant autocorrelation or partial autocorrelation coefficients.

for $P W\left(T A \_m a x\right) ; \sigma_{P W\left(T A \_m a x\right)}^{2}$ satisfied the white noise assumption $(P>0.05)$.

In addition, the filter $(1-0.463 B)$ was used to prewhiten MY as follows:

$$
P W(M Y)_{t}=(1-0.463 B) M Y_{t}
$$

where $P W(M Y)$ is the prewhitened $\mathrm{MY}$. The $\mathrm{CCF}$ between $P W(M Y)$ and $P W\left(T A \_\max \right)$ is displayed in Figure 4. As shown in Figure 4 (see the positive part of time lags), the first to third orders of lag were significant. The first order of lag had the largest cross-correlation coefficient (absolute value); and the absolute values for cross-correlation coefficients (absolute value) decreased from first to third order of lag in sequence. These results suggested that the response of MY to TA_max delayed $1 \mathrm{~d}$ and persisted $3 \mathrm{~d}$. Furthermore, the strength of lag response of MY decreased over time. As pointed out by Collier et al. (1981) and West et al. (2003), the

\section{PW(MY) vs. PW(TA_max)}

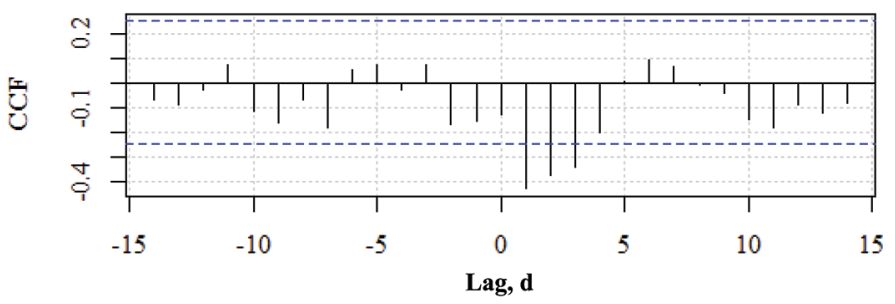

Figure 4. Cross-correlation functions $(\mathrm{CCF})$ for prewhitened milk yield $[\mathrm{PW}(\mathrm{MY})]$ and prewhitened maximum daily ambient temperature [PW(TA_max)]. The dashed lines denote the bounds for CCF. The spikes outside the bounds will be recognized as significant crosscorrelation coefficients.

lag response of milk yield might be related to the lag response of heat strain (e.g., altered feed intake). In other words, the stress of hot climate would trigger the decrease of feed intake, and consequently bring about the decline of milk yield. Thus, the cross correlations between milk yield and feed intake might help explain the pattern of lag response for milk yield. However, the report of cross correlation between milk yield and feed intake seems rare. The data set in this study does not include the data of feed intake and cannot provide more analyses. Further studies on cross correlation between milk yield and feed intake are required to interpret the pattern of lag response for milk yield.

According to the pattern of CCF in Figure 4, the absolute values of cross-correlation coefficients decreased in sequence from first to third order of lag. The first order of lag was significantly not zero (i.e., not white noise); therefore, $b=1$. The first, second, and third showed a clear downward trend; therefore, $s+r-1=$ 0 , and $r=1$. As a result, the orders $(r, s, b)$ were recognized as $(1,0,1)$, and the transfer function $\left[\omega(B)^{-1}\right.$ $\left.\delta(B) B^{b}\right]$ was identified as $B\left(1-\zeta_{1} B\right)^{-1}$. Therefore, the transfer function model is as follows:

$$
M Y_{t}=\beta_{0}+\beta_{1} \times M Y_{t-1}+\beta_{2} \times T A \_\max _{t-1}+N_{t},
$$

Table 1. The results ${ }^{1}$ of augmented Dicky-Fuller (ADF) and Kwiatkowski-Phillips-Schmidt-Shin (KPSS) tests

\begin{tabular}{|c|c|c|c|c|c|c|c|}
\hline Item & MY & TA_avg & TA_max & TA_min & THI_avg & THI_max & THI_min \\
\hline $\mathrm{ADF}$ & $-2.97^{* *}$ & -2.03 & $-3.51^{* * *}$ & -1.74 & -1.89 & -2.34 & -1.76 \\
\hline KPSS & 0.30 & $0.98^{* * *}$ & $0.40^{*}$ & $1.04^{* * *}$ & $1.05^{* * *}$ & $0.91^{* * *}$ & $1.05^{* * *}$ \\
\hline
\end{tabular}
for input and output series

${ }^{1}$ The null hypothesis is nonstationary for the ADF test and stationary for the KPSS test. The 1-sided critical values for ADF (with drift) are $-3.51,-2.89$, and -2.58 at $1 \%, 5 \%$, and $10 \%$, respectively; those for KPSS are $0.74,0.46$, and 0.35 at $1 \%, 5 \%$, and $10 \%$, respectively. MY is the output series; TA_avg, TA_max, TA_min, THI_avg, THI_max, and THI_min are the input series. MY is daily milk yield; TA_avg, TA_max, and TA_ min are the average, maximum, and minimum of daily ambient temperature, respectively; THI_avg, THI_max, and THI_min are the average, maximum, and minimum for daily temperature-humidity index, respectively. $* * *, * *$, and $*$ denote $1 \%, 5 \%$, and $10 \%$ significance levels, respectively. 
where $\beta_{0}$ is the intercept, $\beta_{1}$ and $\beta_{2}$ are the coefficients of $M Y_{t-1}$ and TA_max $x_{t-1}$, respectively. To recognize the process of $N_{t}$, we performed the linear regression, and $N_{t}$ satisfied white noise assumption $(P>0.05)$. Thus, the transfer function model is as follows:

$$
\begin{gathered}
M Y_{t}=16.90( \pm 3.1)+0.74( \pm 0.06) M Y_{t-1}- \\
0.25( \pm 0.05) T A \_\max _{t-1}+ \\
N_{t}, R^{2}=0.817, N_{t} \sim N(0,0.62) .
\end{gathered}
$$

The fitted effect of Eq. 1 is shown in Figure 5a. As shown in Figure 5a, the predicted MY calculated from Eq. 1 clearly tracked the change of MY series.

a
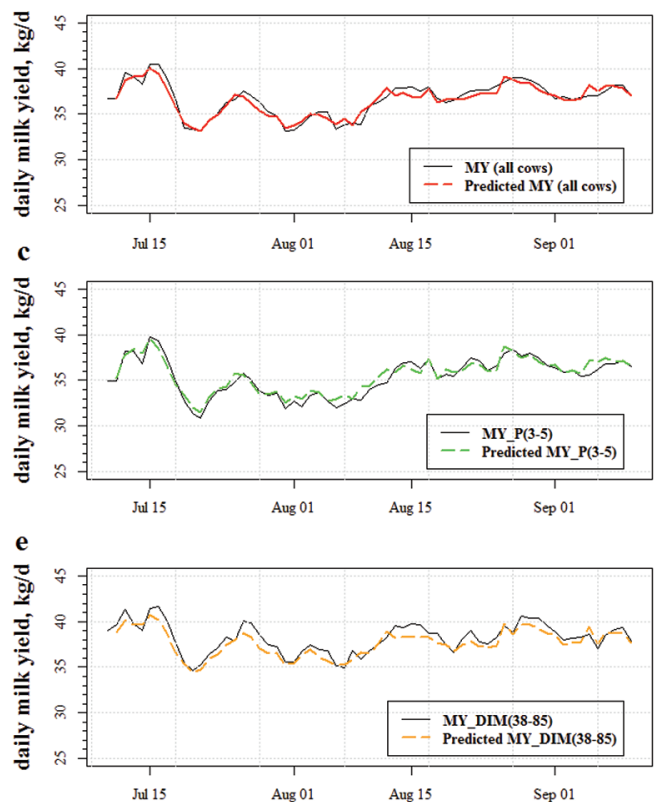

g

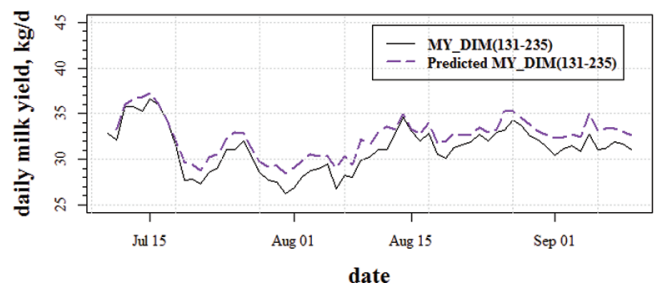

Previous studies suggest that daily milk yield is also influenced by parity and the lactation stage (Jaffrezic et al., 2002; Hansen et al., 2006). Thus, we further examined the predictive effects of Eq. 1 on cows with different parity and DIM intervals. The data set was divided into 2 parts with parity: parity 1 to $2[\mathbf{P}(\mathbf{1}-\mathbf{2})]$ and parity 3 to $5[\mathbf{P}(\mathbf{3}-\mathbf{5})]$. The predictive effects of Eq. 1 on cows with $\mathrm{P}(1-2)$ and $\mathrm{P}(3-5)$ are shown in Figure $5 \mathrm{~b}$ and $5 \mathrm{c}$, respectively. The predicted $\mathrm{MY}$ for $\mathrm{P}(1-2)$ and $\mathrm{P}(3-5)$ were in accordance with the MY for both $\mathrm{P}(1-2)$ and $\mathrm{P}(3-5)$, respectively (Figure $5 \mathrm{~b}$ and $5 \mathrm{c}$ ). In Figure $6 \mathrm{a}, \mathrm{MY}$ for $\mathrm{P}(1-2)$ and $\mathrm{P}(3-5)$ [MY_P(1-2) and MY_P(3-5)] were shifted to the same starting point $(36.7 \mathrm{~kg} / \mathrm{d})$; from Figure $6 \mathrm{a}$, the series of $\mathrm{MY} \_\mathrm{P}(1-2)$

b
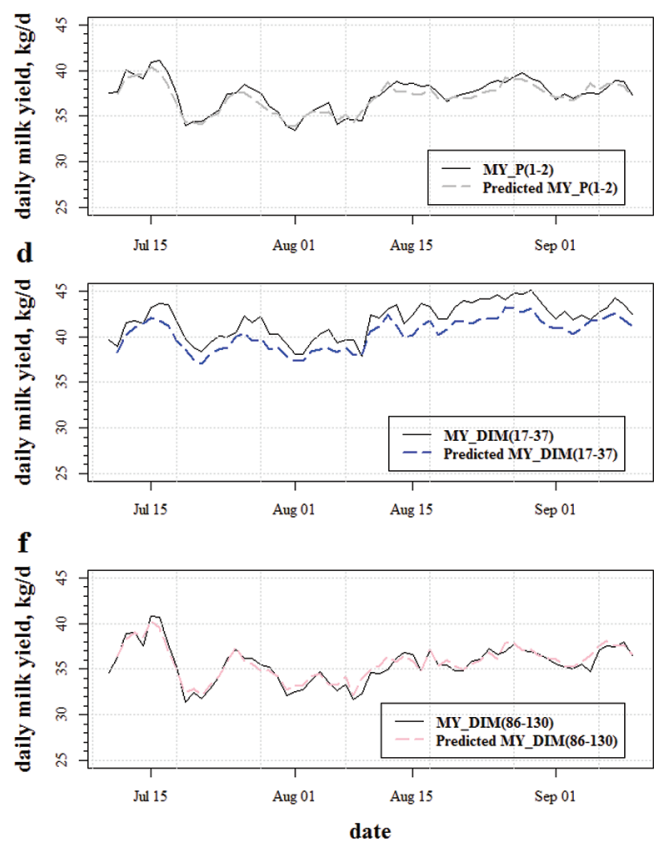

Figure 5. Time series plots for mean daily milk yield (MY) series and the predicted series calculated from the transfer function model (Eq. 1). $\mathrm{P}(1-2)$ and $\mathrm{P}(3-5)$ represent parity $1-2$ (81 cows) and 3-5 (42 cows), respectively; and $\mathrm{MY} \_\mathrm{P}(1-2)$ and $\mathrm{MY}-\mathrm{P}(3-5)$ are the $\mathrm{MY}$ for cows of $\mathrm{P}(1-2)$ and $\mathrm{P}(3-5)$, respectively. Ranges $17-37,38-85,86-130$, and 131-235 are DIM intervals for the first (31 cows), second (31 cows), third (31 cows), and fourth (30 cows) quartile of DIM (the individual DIM records on the first test day), respectively. MY_DIM(17-37), MY_ DIM(38-85), MY_DIM(86-130), and MY_DIM(131-235) are the MY for cows of DIM(17-37), DIM(38-85), DIM(86-130), and DIM(131-235), respectively. (a) MY (all 123 cows) vs. predicted MY; (b) MY_P(1-2) vs. predicted MY_P(1-2); (c) MY_P(3-5) vs. predicted MY_P(3-5); (d) MY_DIM(17-37) vs. predicted MY_DIM(17-37); (e) MY_DIM(38-85) vs. predicted MY_DIM(38-85); (f) MY_DIM(86-130) vs. predicted MY_DIM(86-130); (g) MY_DIM(131-235) vs. predicted MY_DIM(131-235). 
and MY_P(3-5) were similar. These results implied that parity had less influence on the predictive effects of Eq. 1.

Additionally, the data set was divided into 4 parts $[\operatorname{DIM}(17-37), 31$ cows; $\operatorname{DIM}(38-85), 31$ cows; $\operatorname{DIM}(86-130), 31$ cows; and $\operatorname{DIM}(131-235), 30$ cows] based on the first, second, third, and fourth quartile of DIM, respectively (partitioning the data set with individual DIM records on the first test day). The predictive effects of Eq. 1 on cows with $\operatorname{DIM}(17-37)$, $\operatorname{DIM}(38-85), \operatorname{DIM}(86-130)$, and $\operatorname{DIM}(131-235)$ are displayed in Figure 5d, 5e, 5f, and 5g, respectively. In Figure 5d, although the predicted values of Eq. 1 tracked the fluctuation of the MY of $\operatorname{DIM}(17-37)$, the most predicted MY fell below MY (the predicted MY were about $1.5 \mathrm{~kg} / \mathrm{d}$ lower than MY on average). In contrast, the predicted MY were about $1.3 \mathrm{~kg} / \mathrm{d}$ higher than MY of DIM(131-235) on average. In Figure 6b, to compare trend information more easily, the MY for $\operatorname{DIM}(17-37)$ and DIM(131-235) [MY_DIM(17-37) and MY_DIM(131-235)] were shifted to the same starting point $(36.7 \mathrm{~kg} / \mathrm{d})$; from Figure 6b, MY_DIM(17-37)
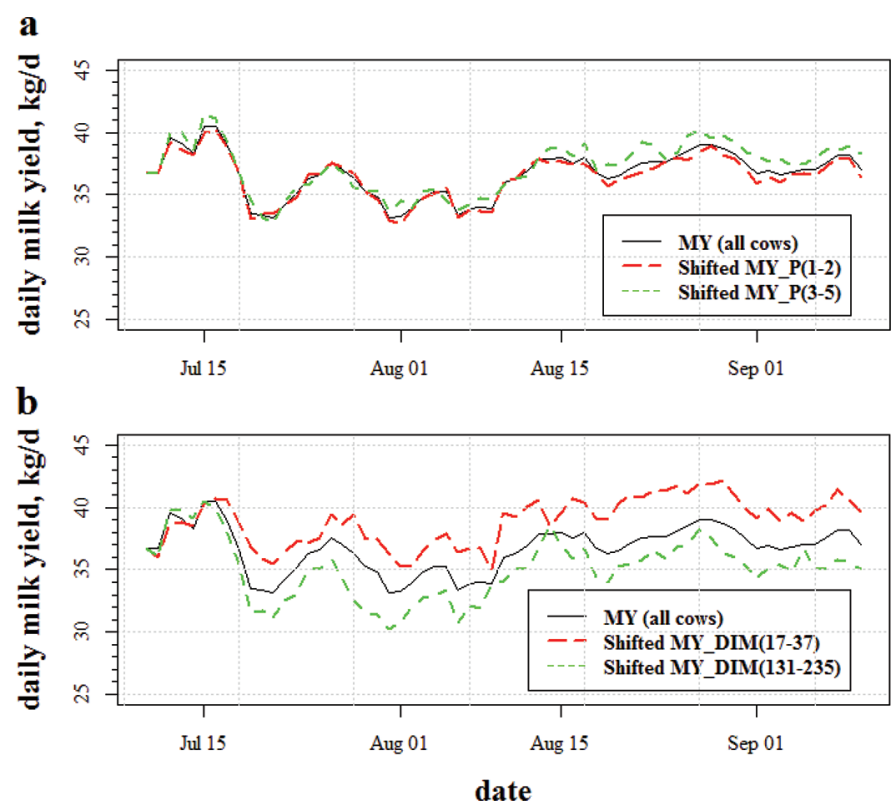

Figure 6. The differences of time series of mean daily milk yield (MY) between (a) parity intervals and (b) between DIM intervals. To recognize the trend information more easily, the series were shifted to the same start point $[36.7 \mathrm{~kg} / \mathrm{d}$; the first data point of the MY series (all cows)] by adding fixed values to the all data points in the series [i.e., shifting series by adding $-0.9,1.8,-2.9$, and 3.9 to all data points of MY_P(1-2), MY_P(3-5), MY_DIM(17-37), and MY_DIM(131-235), respectively]. MY_P(1-2) and MY_P(3-5) are the milk yield for parity $1-2$ and 3-5, respectively; MY_DIM(17-37) and MY_DIM(131-235) are the milk yield for DIM range 17-37 and $131-235$, respectively. and MY_DIM(131-235) showed uptrend and downtrend compared with the MY for all cows, respectively.

The uptrend of the MY for $\operatorname{DIM}(17-37)$ and downtrend of the MY for DIM(131-235) are in line with the theory of lactation curve. According to lactation curve theory, the MY for early lactation, $\operatorname{DIM}(17-37)$, would have an upward trend in the following 2 mo; in contrast, the MY for mid or late lactation, DIM(130-235), would have a downward trend in the following 2 mo (Silvestre et al., 2009; López et al., 2015). The difference between the MY and predicted MY for cows with $\operatorname{DIM}(17-37)$ and $\operatorname{DIM}(131-235)$ might be due to the reason that Eq. 1 is built under the stationary assumption that the series does not contain trend information. The stationarity of MY might be because the uptrend and downtrend of MY for cows in different lactation stages offset each other. Therefore, Eq. 1 is appropriate for the herds with no clear trend of MY. The trend information of MY can be combined by inputting adjustment factors. For instance, the uptrend can be corrected by adjusting the intercept (plus $1.5 \mathrm{~kg} / \mathrm{d}$ ) of Eq. 1 when predicting MY_DIM(17-37); similarly, the downtrend can be corrected by reducing the intercept of Eq. 1 by $1.3 \mathrm{~kg} / \mathrm{d}$ when predicting MY_DIM(131-235). More adjustment factors for DIM can be given if dividing DIM into smaller intervals. However, if dividing a data set into more than 4 parts, the number of cows in each interval will be smaller than 30 (30 is the lower limit of large sample). Therefore, the adjustment factors for DIM are not given in this paper. Further work should be undertaken to develop the adjustment factors for DIM based on a larger sample.

In conclusion, the time series of MY and TA_max constitute a dynamic system. In this dynamic system, MY had a lag response of $1 \mathrm{~d}$ after the test day to TA max, and the lag response would last for $3 \mathrm{~d}$. A transfer function model combining $M Y_{t-1}$ and $T A_{-} \max _{t-1}$ was built to predict $M Y_{t}$. The predicted $\mathrm{MY}$ calculated from the transfer function model (Eq. 1) was clearly in line with the fluctuation of MY over time, suggesting that the Eq. 1 can be used to describe and predict the process of MY.

\section{ACKNOWLEDGMENTS}

The researchers are grateful to Zhongdi dairy farm, Beijing, for letting us collect the data. We gratefully acknowledge the financial support of the National Key R\&D Program of China (2016YFD0500507,2017YFD0502003; Beijing, China), the Beijing Dairy Industry Innovation Team Project (BAIC06-2020; Beijing, China), and the Agricultural Science and Technology Innovation Program (ASTIP-IAS07; Beijing, China). The authors have not stated any conflicts of interest. 


\section{REFERENCES}

Ammer, S., C. Lambertz, and M. Gauly. 2016. Is reticular temperature a useful indicator of heat stress in dairy cattle? J. Dairy Sci. 99:10067-10076. https://doi.org/10.3168/jds.2016-11282.

Bisgaard, S., and M. Kulahci. 2011. Chapter 8: Transfer function models. Pages 203-237 in Time Series Analysis and Forecasting by Example, first ed. John Wiley \& Sons Inc. Hoboken, New Jersey.

Bohlouli, M., J. Shodja, S. Alijani, and A. Eghbal. 2013. The relationship between temperature-humidity index and test-day milk yield of Iranian Holstein dairy cattle using random regression model. Livest. Sci. 157:414-420. https://doi.org/10.1016/j.livsci.2013.09 .005 .

Bouraoui, R., M. Lahmar, A. Majdoub, M. Djemali, and R. Belyea. 2002. The relationship of temperature-humidity index with milk production of dairy cows in a Mediterranean climate. Anim. Res. 51:479-491. https://doi.org/10.1051/animres:2002036.

Box, G. E., G. M. Jenkins, G. C. Reinsel, and G. M. Ljung. 2015. Chapter 12: Identification, fitting, and checking of transfer function models. Time Series Analysis: Forecasting and Control, fifth ed. John Wiley \& Sons Inc. Hoboken, New Jersey. 428-461.

Collier, R. J., G. E. Dahl, and M. J. VanBaale. 2006. Major advances associated with environmental effects on dairy cattle. J. Dairy Sci. 89:1244-1253. https://doi.org/10.3168/jds.S0022-0302(06)72193 -2 .

Collier, R. J., R. M. Eley, A. K. Sharma, R. M. Pereira, and D. E. Buffington. 1981. Shade management in subtropical environment for milk yield and composition in Holstein and Jersey cows. J. Dairy Sci. 64:844-849. https://doi.org/10.3168/jds.S0022-0302(81)82656 -2 .

Collier, R. J., B. J. Renquist, and Y. Xiao. 2017. A 100-year review: Stress physiology including heat stress. J. Dairy Sci. 100:1036710380. https://doi.org/10.3168/jds.2017-13676.

Deluyker, H. A., R. H. Shumway, W. E. Wecker, A. S. Azari, and L. D. Weaver. 1990. Modeling daily milk yield in Holstein cows using time series analysis. J. Dairy Sci. 73:539-548. https://doi.org/10 .3168/jds.S0022-0302(90)78701-2.

Hansen, J. V., N. C. Friggens, and S. Højsgaard. 2006. The influence of breed and parity on milk yield, and milk yield acceleration curves. Livest. Sci. 104:53-62. https://doi.org/10.1016/j.livsci 2006.03.007.

Heinicke, J., S. Ibscher, V. Belik, and T. Amon. 2019. Cow individual activity response to the accumulation of heat load duration. J. Therm. Biol. 82:23-32. https://doi.org/10.1016/j.jtherbio.2019.03 .011 .

Jaffrezic, F., I. M. S. White, R. Thompson, and P. M. Visscher. 2002. Contrasting models for lactation curve analysis. J. Dairy Sci. 85:968-975. https://doi.org/10.3168/jds.S0022-0302(02)74156-8.

Jensen, D. B., M. van der Voort, and H. Hogeveen. 2018. Dynamic forecasting of individual cow milk yield in automatic milking systems. J. Dairy Sci. 101:10428-10439. https://doi.org/10.3168/jds .2017-14134.
Lenis, G., M. Kircher, J. Lázaro, R. Bailón, E. Gil, and O. Doessel. 2017. Separating the effect of respiration on the heart rate variability using Granger's causality and linear filtering. Biomed. Signal Process. Control 31:272-287. https://doi.org/10.1016/j.bspc .2016.07.014.

López, S., J. France, N. E. Odongo, R. A. McBride, E. Kebreab, O. AlZahal, B. W. McBride, and J. Dijkstra. 2015. On the analysis of Canadian Holstein dairy cow lactation curves using standard growth functions. J. Dairy Sci. 98:2701-2712. https://doi.org/10 .3168/jds.2014-8132.

NRC. 1971. A Guide to Environmental Research on Animals. National Academies. Natl. Acad. Sci., Washington, DC.

Shumway, R. H., and D. S. Stoffer. 2017. Chapter 5.5: Lagged regression and transfer function modeling. Pages 266-287 in Time Series Analysis and its Applications: With R examples, fourth ed. Springer International Publishing AG. Berlin, Germany.

Silvestre, A. M., A. M. Martins, V. A. Santos, M. M. Ginja, and J. A. Colaço. 2009. Lactation curves for milk, fat and protein in dairy cows: A full approach. Livest. Sci. 122:308-313. https://doi.org/10 .1016/j.livsci.2008.09.017.

Smith, D. L., T. Smith, B. J. Rude, and S. H. Ward. 2013. Short communication: Comparison of the effects of heat stress on milk and component yields and somatic cell score in Holstein and Jersey cows. J. Dairy Sci. 96:3028-3033. https://doi.org/10.3168/jds.2012 $-5737$.

West, J. W. 2003. Effects of heat-stress on production in dairy cattle. J. Dairy Sci. 86:2131-2144. https://doi.org/10.3168/jds.S0022 $-0302(03) 73803-X$.

West, J. W., B. G. Mullinix, and J. K. Bernard. 2003. Effects of hot, humid weather on milk temperature, dry matter intake, and milk yield of lactating dairy cows. J. Dairy Sci. 86:232-242. https://doi .org/10.3168/jds.S0022-0302(03)73602-9.

Wildridge, A. M., P. C. Thomson, S. C. Garcia, A. J. John, E. C. Jongman, C. E. Clark, and K. L. Kerrisk. 2018. The effect of temperature-humidity index on milk yield and milking frequency of dairy cows in pasture-based automatic milking systems. J. Dairy Sci. 101:4479-4482. https://doi.org/10.3168/jds.2017-13867.

Zeng, Y., A. M. Parkhurst, and J. Pantoja. 2009. Using time series to study effect of air temperature on body temperature of cows in Puerto Rico. Annual Conference on Applied Statistics in Agriculture, Manhattan, KS. New Prairie Press, Manhattan, KS. https:/ /doi.org/10.4148/2475-7772.1086.

\section{ORCIDS}

Gan Li @ https://orcid.org/0000-0002-0031-5841

Jian Chen $\odot$ https://orcid.org/0000-0001-9340-2022

Dandan Peng (i) https://orcid.org/0000-0002-4247-1535

Xianhong Gu (๑) https://orcid.org/0000-0002-2032-3179 